
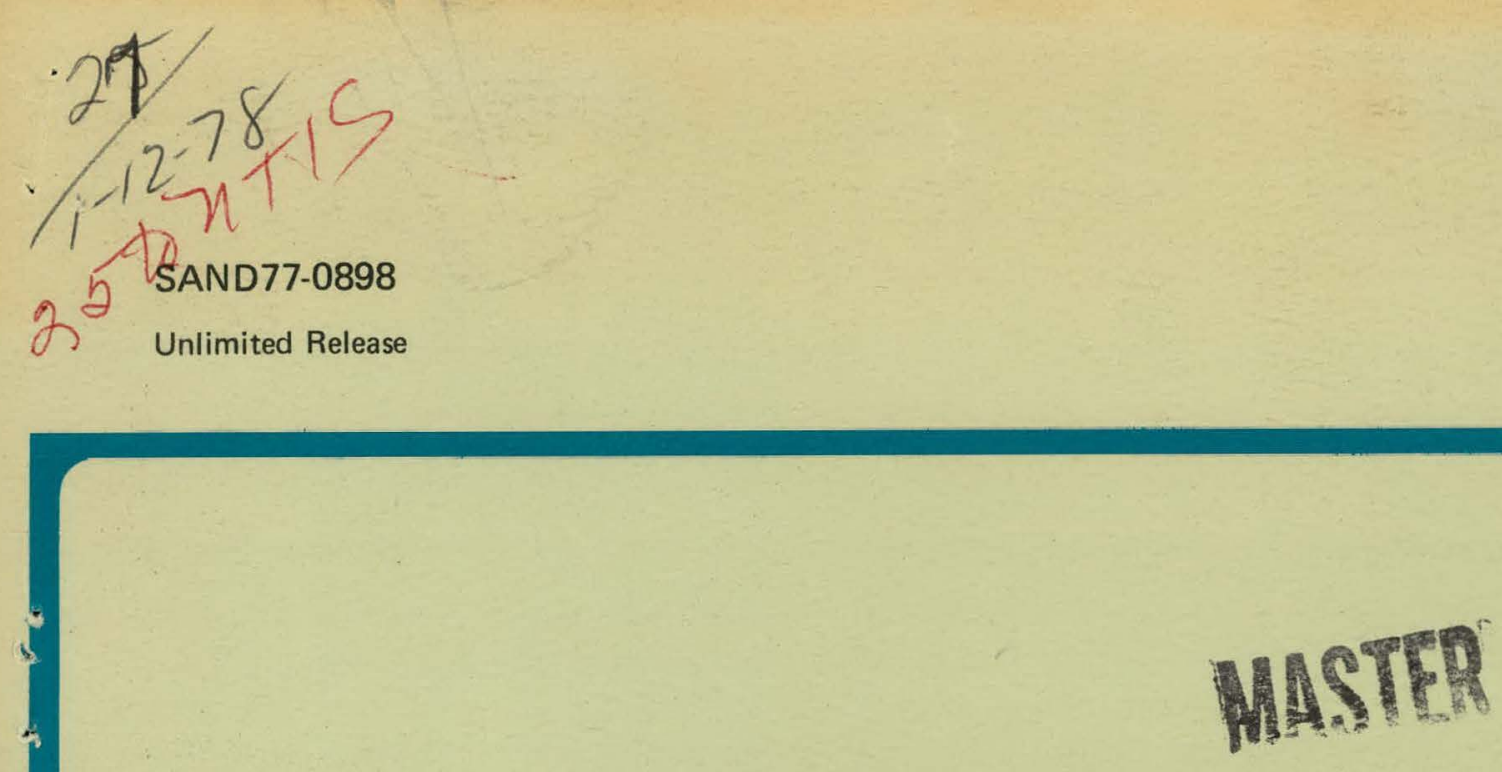

\title{
Basic Linear Algebra Subprograms for FORTRAN Usage
}

Chuck L. Lawson, Richard J. Hanson, David R. Kincaid, Fred T. Krogh

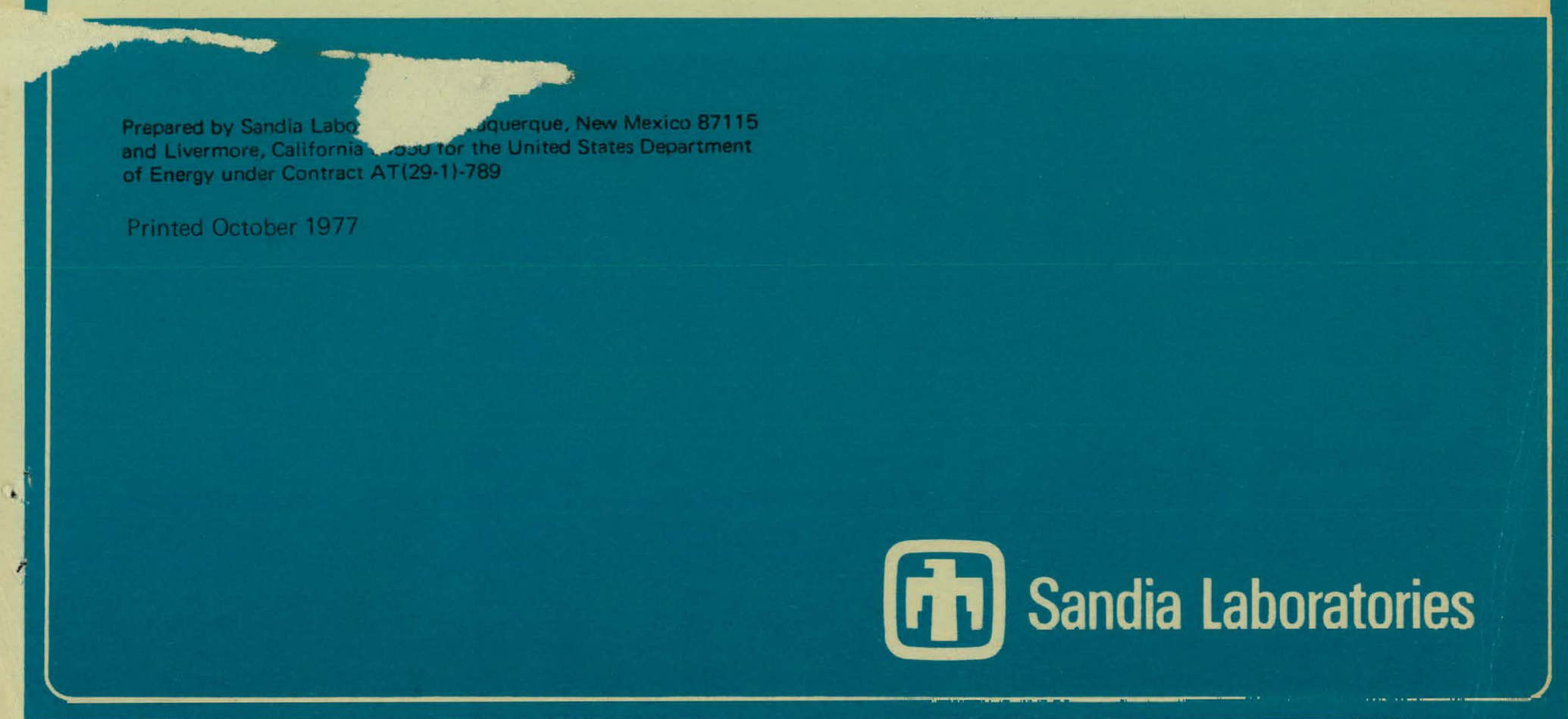

SF $2900 Q(7-73)$ 


\section{DISCLAIMER}

This report was prepared as an account of work sponsored by an agency of the United States Government. Neither the United States Government nor any agency Thereof, nor any of their employees, makes any warranty, express or implied, or assumes any legal liability or responsibility for the accuracy, completeness, or usefulness of any information, apparatus, product, or process disclosed, or represents that its use would not infringe privately owned rights. Reference herein to any specific commercial product, process, or service by trade name, trademark, manufacturer, or otherwise does not necessarily constitute or imply its endorsement, recommendation, or favoring by the United States Government or any agency thereof. The views and opinions of authors expressed herein do not necessarily state or reflect those of the United States Government or any agency thereof. 


\section{DISCLAIMER}

Portions of this document may be illegible in electronic image products. Images are produced from the best available original document. 
Issued by Sandia Laboratories, operated for the United States Energy Research \& Development Administration by Sandia Corporation.

\section{NOTICE}

This report was prepared as an account of work sponsored by the United States Government. Neither the United States nor the United States Energy Research \& Development Adminis. tration, nor any of their employees, nor any of their con. tractors, subcontractors, or their employees, makes any warranty, express or implied, or assumes any legal liability or responsibility for the accuracy, completeness or usefulness of any information, apparatus, product or process disclosed, or represents that its use would not infringe privately owned rights.

SF $1004.0 F(3.75)$ 


\author{
SAND77-0898 \\ Unlimited Release \\ Printed October 1977
}

BASIC LINEAR ALGEBRA SUBPROGRAMS FOR FORTRAN USAGE

C. L. Lawson, Jet Propulsion Laboratory

R. J. Hanson, Sandia Laboratories, Albuquerque

D. R. Kincaid, University of Texas, Austin

F. T. Krogh, Jet Propulsion Laboratory

\begin{abstract}
A package of 38 low-level subprograms for many of the basic operations of numerical linear algebra is presented. The package is intended to be used with FORTRAN. The operations in the package are dot products, elementary vector operations, Givens transformations, vector copy and swap, vector norms, vector scaling, and the indices of components of largest magnitude.

The subprograms and a test driver are available in portable FORTRAN. Versions of the subprograms are also provided in assembly language for the IBM $360 / 67$, the CDC 6600 and CDC 7600, and the Univac 1108 .
\end{abstract}

NoTICE

This report was prepared as an account of work sponsored by the United States Goveusulent. Neticher the United States nor the United States Department of Energy, nor sny of their employees, nor any of their contraotors, subeontractors, on deis enployes, makes any warranty, express or implied, or asumes, makes liability or responsibility for the accuracy comple legal ns usefulness of any informe accuracy, comple teness process discrlnsed, of represents, apparatus, proviluat us infringe privately owned rights. that its use would not
Printed in the United States of America

Available f'rom

National Technical Information Service

U.S. Department of Commerce

5285 Port Royal Road

Springfield, Virginia 22161

Price: \$4. 
Table of Contents

Page

1. Inlruduction .............. 3

2. Redsuns for Jevieloping the Package ........ 4

3. Scope of the Package . . . . . . . . 5

4. Programming Conventions ......... 8

5. Specification of the BLA Subprograms . . . . 9

6. Implementation .............. 15

7. Relation to the ANSI FORTRAN Standard ..... 16

8. Testing ................ 17

9. Selected Timing Results ........... . 19

Acknowledgements . . . . . . . . 23

References .............. 24

Appendix 1 The Modified Givens Transformation • 25

Appendix 2 Extended Timing Results for Some Operations ............ 29

Appendix 3 Sample Usage of the BLAS in FORTRAN Programming ........ 33 
BASIC LINEAR ALGEBRA SUBPROGRAMS

FOR FORTRAN USAGE

C. L. Lawson, Jet Propulsion Laboratory

R. J. Hanson, Sandia Laboratories, Albuquerque

D. R. Kincaid, University of Texas, Austin

F. T. Krogh, Jet Propulsion Laboratory

\section{Introduction}

This paper describes a package, called the BLAS, of thirty-eight FORTRAN-callable subprograms for basic operations of numerical linear algebra. This paper and the associated package of subprograms and testing programs are the result of a collaborative voluntary project of the ACMSIGNUM committee on basic linear algebra subprograms. This project was carried out during the period 1973-1977.

The initial version of the subprogram specifications appeared in Ref. [1]. Following distribution of Ref. [1] to persons active in the development of numerical linear algebra software, open meetings of the project were held at the Purdue Mathematical Software II Conference, May, 1974, Ref: [2], and at the National Computer Conference, Anaheim, May, 1975. Extensive modifications of the specifications were made following the Purdue meeting which was attended by thirty people. A few additional changes resulted from the Anaheim meeting. Most of the further Fortran code changes resulted from an effort to improve the design and to make them more robust. 


\section{Reasons for Developing the Package}

Designers of computer programs involving linear algebraic operations have frequently chosen to implement certain low-level operations such as the dot product as separate subprograms. This may be observed both in many published codes and in codes written for specific applications at many computer installations. Following are some of the reasons for taking this approach:

(1) It can serve as a conceptual aid in both the design and coding slayes of a programming effort to regard an operation such as the dot product as a basic building hlock. This is consistent with. the ideas of structured programing which encourage modularizing common code sequences.

(2) It improves the self-documenting quality of code to identify an operation such as the dot product by a unique mnemonic name.

(3) Since a significant amount of the execution time in complicated linear algebraic programs may be spent in a few low-level operations, a reduction of execution time spent in these operations may be reflected in cost savings in the running of programs. Assembly language coded subprograms for these operations provide such savings on some computers.

(4) The programming of some of these low-level operations involves algorithmic and implementation subtleties that are likely to be ignored in the typical applications programming environment. For example the subprograms provided for the modified Givens transformation incorporate control of the scaling terms which otherwise can drift monotonically toward underflow.

If there could be general agreement on standard names and parameter lists for some of these basic operations it would add the additional benefit of portability with efficiency on the assumption that the assembly language subprograms were generally available. Such standard subprograms would provide building blocks with which designers of portable subprograms for higher level linear algebraic operations such as solving linear algebraic equations, 
eigenvalue problems, etc., could achieve additional efficiency. The package of subprograms described in this paper is proposed to serve this purpose.

\section{Scope of the Package}

Specifications will be given for thirty-eight FORTRAN-callable subprograms covering the operations of dot product, vector plus a scalar times a vector, Givens transformation, modified Givens transformation, copy, swap, Euclidean norm, sum of magnitudes, multiplying a scalar times a vector, and locating an element of largest magnitude. Since we are thinking of these subprograms as being used in an ANS FORTRAN context we provide for the cases of single precision, double precision, and (single precision) complex data.

In Table 1 a concise summary of the operations provided and the conventions adopted for naming the subprograms is given. Each type of operation is identified by a root name. The root name is prefixed by one or more of the letters I, S, D, C, or Q. to denote operations on integer, single precision, double precision, (single precision) complex, or extended precision data types, respectively. For subprograms involving a mixture of data types the type of the output quantity is indicated by the left-most prefix letter. Suffix letters are used on four of the dot product subprograms to distinguish variants of the basic operation.

If one were to extend this package to include double precision complex type data (COMPLEX*16 in IBM FORTRAN) we suggest that the prefix $\mathrm{Z}$ be used in the names of the new subprograms. For example, subprograms CZIOTC and CZDOTU for the dot product of (single precision) complex vectors, with double precision accumulation, have been written for the CDC 6600 . These may be obtained dirert.ly from Kincaid. 
Table 1

Sumrary of Functions and Names

of the Basic Linear Algebra Subprograms

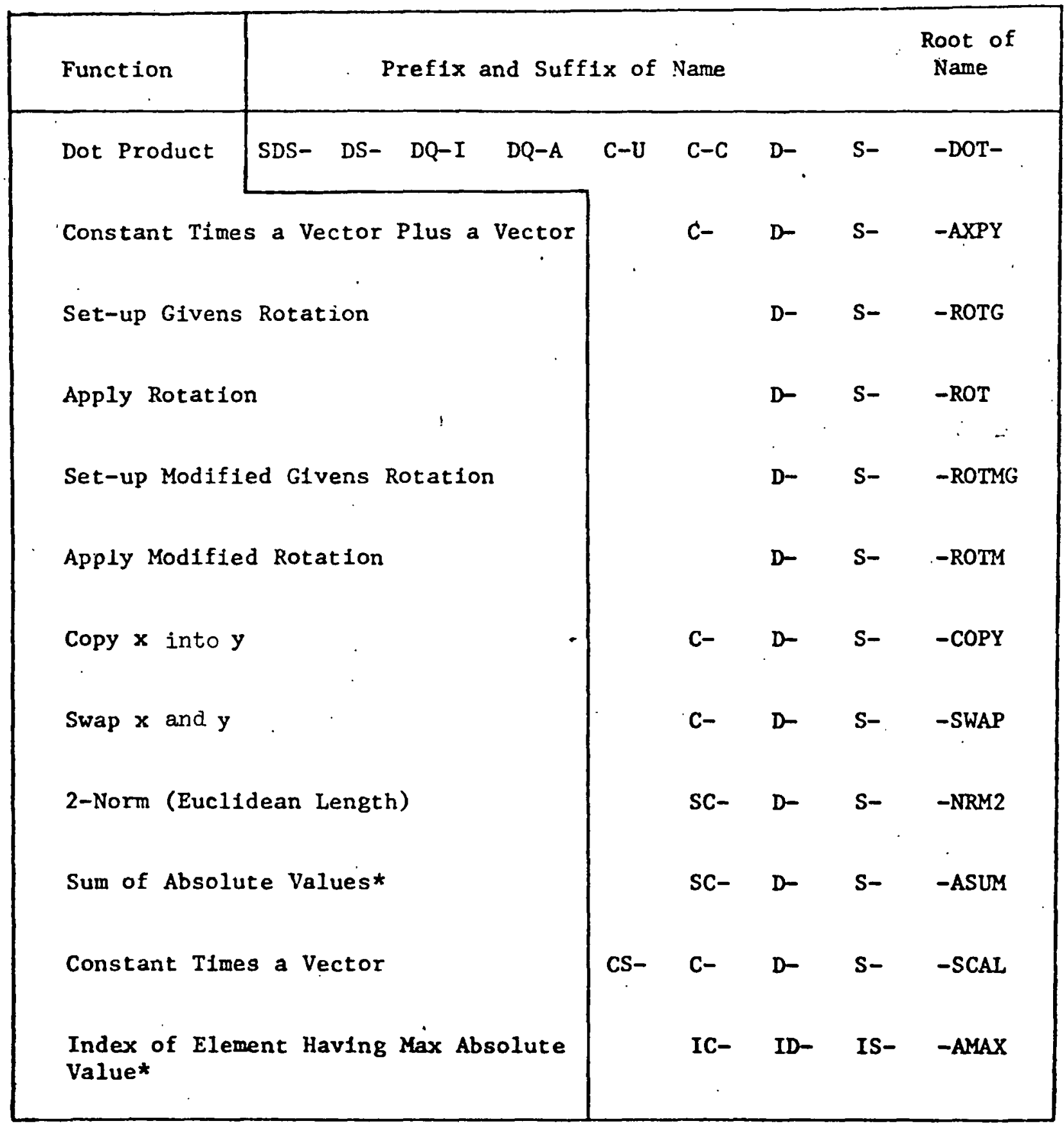

*For complex components $z_{j}=x_{j}+1 y_{j}$ these subprograms compute $\left|x_{j}\right|+\left|y_{f}\right|$ instead of $\left(x_{j}^{2}+y_{f}^{2}\right)^{1 / 2}$. 
Section 5 lists all of the subprogram names and their parameter lists; and defines the operations performed by each subprogram.

The criterion for including an operation in the package was that it should involve just one level of looping and occur in the usual algorithms of numerical linear algebra such as Gaussian elimination or the various elimination methods using orthogonal transformations.

This orientation affected the specifications of SCASUM and ICAMAX particularly. Although SASUM and DASUM compute $\ell_{1}$ norms we assumed that the usage of either of these subprograms in numerical linear algebra software would be for the purpose of computing a vector norm that was less expensive to compute than the $l_{2}$ norm. Thus for the complex version, SCASUM, instead of specifying the $\ell_{1}$ norm which would be

$$
w=\sum_{i}\left\{\left[\operatorname{Re}\left(x_{i}\right)\right]^{2}+\left[\operatorname{Im}\left(x_{i}\right)\right]^{2}\right\}^{1 / 2}
$$

we specified the less expensive norm,

$$
w=\sum_{i}\left\{\left|\operatorname{Re}\left(\mathrm{x}_{i}\right)\right|+\left|\operatorname{Im}\left(\mathrm{x}_{i}\right)\right|\right\} \text {. }
$$

Similarly, whereas ISAMAX and IDAMAX may be regarded as determining the $l_{\infty}$ norm of a vector, we do not regard this as the essential property to be carried over to the complex case. Thus ICAMAX is specified to find an index $j$ such that

$$
\left|\operatorname{Re}\left(\mathrm{x}_{j}\right)\right|+\left|\operatorname{Im}\left(\mathrm{x}_{j}\right)\right|=\max _{i}\left\{\left|\operatorname{Re}\left(\mathrm{x}_{i}\right)\right|+\left|\operatorname{Im}\left(\mathrm{x}_{i}\right)\right|\right\}
$$

rather than finding an index $j$ such that

$$
\left[\operatorname{Re}\left(\mathrm{x}_{j}\right)\right]^{2}+\left[\operatorname{Im}\left(\mathrm{x}_{j}\right)\right]^{2}=\max _{i}\left\{\left[\operatorname{Re}\left(\mathrm{x}_{i}\right)\right]^{2}+\left[\operatorname{Im}\left(\mathrm{x}_{i}\right)\right]^{2}\right\}
$$

In both the computation of the $l_{2}$ norm and the Givens transformation 
a naive computation of the squares of the given data would restrict. the exponent range of acceptable data. This package avoids this restriction by making use of ideas described by Cody, Ref. [11], and Blue, Ref. [12]. Additionally, in the case of the Givens transformations, an idea of Stewart, Ref. [13], permits the storage of all the transformations of a matrix decomposition in the memory space occupied by the elements zeroed by the transformation.

The modified Givens transformation is a relatively new innovation among numerical linear algebra algorithms, Refs. [3], [4], and [5]. The significant features are the reduction of the number of multiplications, the elimination of square root operations, and the capability of removing rows of data in least squares problems. The details of this algorithm as implemented in this package are given in the Appendix.

\section{Programing Conventions}

Vector arguments are permitted to have a storage spacing vetween elements. This spacing is specified by an increment parameter. For example, suppose a vector $x$ having components $x_{i}, i=1, \ldots, N$ is stored in a DOUBLE PRECISION array DX( ) with increment parameter INCX. If INCX $\geq 0$ then $x_{i}$ is stored in $\mathrm{DX}(1+(i-1) * \operatorname{INCX})$. If $\operatorname{INCX}<0$ then $x_{i}$ is stored in $\operatorname{DX}(1+(N-i) *|\operatorname{INCX}|)$. This method of indexing when INCX $<0$ avoids negative indices in the array IX ( ) and thus permits the subprograms to be written in FORTRAN. Only positive values of INCX are allowed for operations 26-38 that each have a single vector argument.

It is intended that the loops in all subprograms process the elements of vector arguments in order of increasing vector component indices, i.e., in the order $x_{i}, i=1, \ldots, N$. This implies processing in reverse storage order when INCX $<0$. If these subprograms are implemented on a computer having 
parallel processing capability, it is recommended that this order of processing be adhered to as nearly as is reasonable.

\section{Specification of the BLA Subprograms}

Type and dimension information for variables occurring in the subprogram specifications are as follows:

$$
\begin{aligned}
& \mathrm{mx}=\max \left(1, \mathbb{N}^{*}|\operatorname{INCX}|\right) \\
& \mathrm{my}=\max \left(1, \mathrm{~N}^{*}|\operatorname{INCY}|\right)
\end{aligned}
$$

$\begin{array}{ll}\text { INTEGER } & \quad \mathrm{N}, \text { INCX, INCY , IMAX } \\ \text { REAL } & \mathrm{SC}(\mathrm{mx}), \mathrm{SY}(\mathrm{my}), \mathrm{SA}, \mathrm{SB}, \mathrm{SC}, \mathrm{SS} \\ \text { REAL } & \mathrm{SDl}, \mathrm{SD} 2, \mathrm{SBI}, \mathrm{SB} 2, \mathrm{SPARAM}(5), \mathrm{SW}, \mathrm{QC}(10) \\ \text { DOUBLE } & \text { PRECISION } \quad \mathrm{DX}(\mathrm{mx}), \mathrm{DY}(\mathrm{my}), \mathrm{DA}, \mathrm{DB}, \mathrm{DC}, \mathrm{DS} \\ \text { DOUBLE } & \text { PRECISION } \quad \mathrm{DDI}, \mathrm{DD} 2, \mathrm{DBl}, \mathrm{DB} 2, \mathrm{DPARAM}(5), \mathrm{DW} \\ \text { COMPLEX } & \mathrm{CX}(\mathrm{mx}), \mathrm{CY}(\mathrm{my}), \mathrm{CA}, \mathrm{CW}\end{array}$

Type declarations for function names are as follows:

INTEGER ISAMAX, IDAMAX, ICAMAX

REAL SDOT, SDSDOT, SINR2, SCNRM2, SASUM, SCASUM

DOUBLE PRECISION DSDOT, DDOT,DQDOTI, DODOTA, DNRM2, DASUM

COMPLEX CDOTC CDOTU

Dot Product Subprograms

1. $\mathrm{SW}=\operatorname{SDOT}(\mathrm{N}, \mathrm{SX}, \mathrm{INCX}, \mathrm{SY}, \mathrm{INCY})$

$w^{*}:=\sum_{i=1}^{N} x_{i} y_{i}$

2. $\mathrm{DW}=\operatorname{DSDOT}(\mathrm{N}, \mathrm{SX}, \mathrm{INCX}, \mathrm{SY}, \mathrm{INCY})$

$$
w:=\sum_{i=1}^{N} x_{i} y_{i}
$$

Double precision accumulation is used within the subprogram DSĒOT.

3. $\mathrm{SW}=\operatorname{SDSDOT}(\mathrm{N}, \mathrm{SB}, \mathrm{SX}, \operatorname{INCX}, \mathrm{SY}, \operatorname{INCY}) \quad \mathrm{w}:=\mathrm{b}+\sum_{i=1}^{N} \mathrm{x}_{i} \mathrm{y}_{i}$ Accumulation of the inner product and addition of $b$ is in double precision. Conversion of the final result to single precision is done the same as the intrinsic function $\operatorname{SNGL}()$. 
4. $\mathrm{DW}=\operatorname{DDOT}(\mathrm{N}, \mathrm{DX}, \mathrm{INCX}, \mathrm{DY}, \mathrm{TNCY}) \quad \mathrm{w}:=\sum_{i=1}^{\mathrm{N}} \mathrm{x}_{\mathrm{i}} \mathrm{y}_{\mathrm{i}}$

5. $\mathrm{DW}=\mathrm{DQDOTI}(\mathrm{N}, \mathrm{DB}, \mathrm{QC}, \mathrm{DX}, \operatorname{INCX}, \mathrm{DY}, \operatorname{INCY}) \mathrm{w}:=\mathrm{c}:=\mathrm{b}+\sum_{i=1}^{\mathrm{N}} \mathrm{x}_{i} \mathrm{y}_{i}$

The input data, $\mathrm{b}, \mathrm{x}$, and $\mathrm{y}$, are converted internally to extended precision. The result is stored in extended precision form in $\mathrm{QC}($ ) and returned in double precision form as the value of the function DQDOTI.

6. $\mathrm{DW}=\mathrm{DQDOTA}(\mathrm{N}, \mathrm{DB}, \mathrm{QC}, \mathrm{DX}, \mathrm{INCX}, \mathrm{DY}, \mathrm{INCY}) \quad \mathrm{w}:=\mathrm{c}:=\mathrm{b}+\mathrm{c}+\sum_{i=1}^{\mathrm{N}} \mathrm{x}_{\mathrm{i}} \mathrm{y}_{\mathrm{i}}$ The input value of $c$ in $Q C()$ is extended precision. The value $c$ must have resulted from a previous execution of DQDOTI or DQDOTA since no other way is provided for defining an extended precision number. The computation is done in extended precision arithmetic and the result is stored in extended precision form in QC( ) and is returned in double precision form as the function value DQDOTA.

7. $\mathrm{CW}=\operatorname{CDOTC}(\mathrm{N}, \mathrm{CX}, \mathrm{INCX}, \mathrm{CY}, \mathrm{INCY}) \quad \mathrm{w}:=\sum_{i=1}^{N} \overline{\mathrm{x}}_{\mathrm{i}} \mathrm{y}_{\mathrm{i}}$ The suffix $C$ on CDOTC indicates that the complex conjugates of the components $x_{i}$ are used.

8. $\mathrm{CW}=\operatorname{CDOTU}(\mathrm{N}, \mathrm{CX}, \operatorname{INCX}, \mathrm{CY}, \mathrm{INCY}) \quad \mathrm{w}:=\sum_{i=1}^{\mathrm{N}} \mathrm{x}_{\mathrm{i}} \mathrm{y}_{\mathrm{i}}$

The suffix $U$ on CDOTU indicates that the vector components $x_{i}$ are used unconjugated.

In the preceding eight subprograms the value of $\sum_{i=1}^{N}$ will be set to zero if $\mathrm{N} \leq \mathrm{O}$.

Elementary Vector Operation $\quad y:=a x+y$

9. CALL SAXPY (N, SA, SX, INCX, SY, INCY) 
10. CALL DAXPY (N,DA, DX, INCX, DY, INCY)

11. CALL CAXPY $(\mathrm{N}, \mathrm{CA}, \mathrm{CX}, \mathrm{INCX}, \mathrm{CY}, \mathrm{INCY})$

If $a=0$ or if $N \leq 0$ these subroutines return immediately.

\section{Construct Givens Plane Rotation}

12. CALI SROTG (SA, SB, SC, SS).

13. CALL DROTG (DA,DB,DC;DS)

Given $a$ and $b$ each of these subroutines computes

$$
\begin{gathered}
\sigma= \begin{cases}\operatorname{sgn}(a) & \text { if }|a|>|b| \\
\operatorname{sgn}(b) & \text { if }|b| \geq|a|\end{cases} \\
r=\sigma\left(a^{2}+b^{2}\right) \quad \begin{array}{ll}
1 / 2 \\
a / r & \text { if } r \neq 0 \\
1 & \text { if } r=0
\end{array}
\end{gathered}
$$

and

$$
s= \begin{cases}b / r & \text { if } \quad r \neq 0 \\ 0 & \text { if } r=0\end{cases}
$$

The numbers $c, s$, and $r$ then satisfy the matrix equation

$$
\left[\begin{array}{cc}
c & s \\
-s & c
\end{array}\right] \cdot\left[\begin{array}{l}
a \\
b
\end{array}\right]=\left[\begin{array}{l}
r \\
0
\end{array}\right]
$$

The introduction of $\sigma$ is not essential to the computation of a Givens rotation matrix but its use permits later stable reconstruction of $c$ and $s$ from just one stored number, an idea due to stewart, Ref. [13]. For this purpose the subroutine also computes

$$
z=\left\{\begin{array}{l}
s \text { if }|a|>|b| \text { or if } a=b=0 \\
1 / c \text { if }|a| \leq|b| \neq 0 \text { and } c \neq 0 \\
1 \text { if }|a| \leq|b| \mid j \neq 0 \text { and } c=0
\end{array}\right.
$$


The subroutines return $\mathrm{r}$ overwriting $a$, and $z$ overwriting $b$, as well as returning $c$ and $s$.

If the user later wishes to reconstruct $c$ and $s$ from $z$ it can be done as follows

$$
\begin{aligned}
& \text { If } z=1 \text { set } c=0 \text { and } s=1 \\
& \text { If }|z|<1 \text { set } c=\left(1-z^{2}\right)^{1 / 2} \text { and } s=z \\
& \text { If }|z|>1 \text { set } r=i / z \text { and } \varepsilon-\left(1-c^{2}\right)^{1 / 2}
\end{aligned}
$$

\section{Apply a Plane Rotation.}

14. CALL $\operatorname{SROT}(\mathrm{N}, \mathrm{SX}, \mathrm{INCX}, \mathrm{SY}, \mathrm{INCYY}, \mathrm{SC}, \mathrm{SS})$

15. CALL DROT(N, DX, INCX, DY, INCY ,DC,DS):

Each of these subroutines computes

$$
\left[\begin{array}{l}
x_{i} \\
y_{i}
\end{array}\right]:=\left[\begin{array}{cc}
c & s \\
-s & c
\end{array}\right] \cdot\left[\begin{array}{c}
x_{i} \\
y_{i}
\end{array}\right] \text { for } i=1, \ldots, N
$$

If $N \leq O$ or if $c=I$ and $s=0$ the subroutines return immediately.

\section{Construct a Modified Givens Transformation}

16. CALI SROTMG (SDI, SD2, SBI, SB2, SPARAM)

17. CALL DROTMG (DDI, DD2, DB', DB2, DPARAM)

The input quantities $d_{1}, d_{2}, b_{1}$, and $b_{2}$ define a 2-vector $\left[a_{1}, a_{2}\right]^{T}$ In partitioned form as

$$
\left[\begin{array}{l}
a_{1} \\
a_{2}
\end{array}\right]=\left[\begin{array}{cc}
a_{1}^{1 / 2} & 0 \\
0 & d_{2}^{1 / 2}
\end{array}\right] \cdot\left[\begin{array}{l}
b_{1} \\
b_{2}
\end{array}\right]
$$

The subroutine determines the modified Givens rotation matrix $H$, as 
defined in Eqs. (A.6) - (A.7) of Appendix 1 that transforms $b_{2}$, and thus $a_{2}$, to zero. A representation of this matrix is stored in the array SPARAM( ) or DPARAM( ) as follows. Locations in PARAM not listed are left unchanged.

$\operatorname{PARAM}(I)=1$

Case of Eq. (A.7)

$h_{12}=1 \quad h_{21}=-1$

$\operatorname{PARAM}(2)=h_{11}$

$\operatorname{PARAM}(5)=\mathrm{h}_{22}$
$\operatorname{PARAM}(1)=0$

Case of Eq. (A.6)

$\mathrm{h}_{11}=\mathrm{h}_{22}=1$

$\operatorname{PARAM}(3)=h_{21}$

$\operatorname{PARAM}(4)=h_{12}$

$$
\begin{aligned}
& \operatorname{PARAM}(1)=-1 \\
& \text { Case of rescaling } \\
& \operatorname{PARAM}(2)=h_{11} \\
& \operatorname{PARAM}(3)=h_{21} \\
& \operatorname{PARAM}(4)=h_{12} \\
& \operatorname{PARAM}(5)=h_{22}
\end{aligned}
$$

In addition $\operatorname{PARAM}(1)=-2$ indicates $H=I$.

The values of $d_{1}, d_{2}$, and $b_{1}$ are changed to represent the effect of the transformation. The quantity $b_{2}$ which would be zeroed by the transformation is left unchanged in storage.

The input value of $d_{1}$ should be nonnegative, but $d_{2}$ can be negative for the purpose of removing data from a least squares problem. Further details can be found in Appendix 1.

\section{Apply a Modified Givens Transformation}

18. CALL SROTM(N, SX, INCX, SY, INCY, SPARAM)

19. CALL $\mathrm{DROTM}(\mathrm{N}, \mathrm{DX}, \mathrm{INCX}, \mathrm{DY}, \mathrm{INCY}, \mathrm{DPARAM})$

Let $\mathrm{H}$ denote the modified Givens transformation defined by the parameter array SPARAM( ) or DPARAM( ). The subroutines compute

$$
\left[\begin{array}{l}
x_{i} \\
y_{i}
\end{array}\right]:=H\left[\begin{array}{l}
x_{i} \\
y_{i}
\end{array}\right] \text { for } i=1, \ldots, N
$$

If $\mathrm{N} \leq \mathrm{O}$ or if $\mathrm{H}$ is an identity matrix the subroutines return immediately. See Appendix I for further details. 
Copy a Vector $\mathrm{x}$ to $\mathrm{y} \quad \mathrm{y}:=\mathrm{x}$

20. CALL SCOPY (N, SX, INCX, SY, INCY)

21. CALL $\mathrm{DCOPY}(\mathrm{N}, \mathrm{DX}, \mathrm{INC} X, \mathrm{DY}, \mathrm{INCY})$

22. CALL $\mathrm{CCOPY}(\mathrm{N}, \mathrm{CX}, \mathrm{INCX}, \mathrm{CY}, \mathrm{INCY})$

Return immediately if $\mathrm{N} \leq 0$.

\section{Interchange Vectors $\mathrm{x}$ and $\mathrm{y} \quad \mathrm{x}:=: \mathrm{y}$}

23. CALL $\operatorname{SSWAP}(N, \mathrm{NX}$, INCX, SY, INCY)

24. CALL DSWAP(N, DX, INCX, DY, INCY)

25. CALL CSWAP(N, CX, INCX, CY, INCY)

Return immediately if $N \leq 0$.

Euclidean Length or $l_{2}$ Norm of a Vector

$w:=\left[\sum_{i=1}^{N}\left|x_{i}\right|^{2}\right]^{1 / 2}$

26. $S W=\operatorname{SNRM} 2(\mathrm{~N}, \mathrm{SX}, \mathrm{INCX})$

27. $\mathrm{DW}=\mathrm{DNRM} 2(\mathrm{~N} ; \mathrm{DX}, \mathrm{INCX})$

28. $\mathrm{SW}=\mathrm{SCNRM} 2(\mathrm{~N}, \mathrm{CX}, \mathrm{INCX})$

If $N \leq 0$ the result is set to zero.

\section{Sum of Magnitudes of Vector Components}

29. $\operatorname{SW}=\operatorname{SASUM}(\mathrm{N}, \mathrm{SX}, \mathrm{INCX})$

30. $\operatorname{IW}=\operatorname{IAUUM}(\mathrm{N}, \mathrm{DX}, \operatorname{INCX})$

31. $\mathrm{SW}=\operatorname{SCASUM}(\mathrm{N}, \mathrm{CX}, \mathrm{INCX})$

The functions SASUM and DASUM compute $w:=\sum_{i=1}^{N}\left|x_{i}\right|$. The function SCASUM computes

$$
w:=\sum_{i=1}^{N}\left\{\left|\operatorname{Real}\left(\mathrm{x}_{i}\right)\right|+\left|\operatorname{Imag}\left(\mathrm{x}_{i}\right)\right|\right\}
$$


These functions return immediately with the result set to zero if $\mathrm{N} \leq 0$.

Vector scaling $\quad x:=a x$

32. CALL $\operatorname{SSCAL}(\mathrm{N}, \mathrm{SA}, \mathrm{SX}, \mathrm{INEX})$

33. CALL DSCAL (N,DA, DX, INCX)

34. CALL $\operatorname{CSCAL}(\mathrm{N}, \mathrm{CA}, \mathrm{CX}, \mathrm{INCX})$

35. CALL $\operatorname{CSSCAL}(\mathrm{N}, \mathrm{SA}, \mathrm{CX}, \mathrm{INCX})$

Return immediately if $\mathrm{N} \leq 0$.

Find Largest Component of a Vector

36. IMAX $=\operatorname{ISAMAX}(\mathrm{N}, \mathrm{SX}, \operatorname{INCX})$

37. $\operatorname{IMAX}=\operatorname{IDAMAX}(\mathrm{N}, \mathrm{DX}, \operatorname{INCX})$

38. $\operatorname{IMAX}=\operatorname{ICAMAX}(\mathrm{N}, \mathrm{CX}, \operatorname{INCX})$

The functions ISAMAX and IDAMAX determine the smallest index $i$ such that $\left|x_{i}\right|=\max \left\{\left|x_{j}\right|: j=1, \ldots, N\right\}$.

The function ICAMAX determines the smallest index $i$ such that $\left|x_{i}\right|=\max \left\{\left|\operatorname{Real}\left(x_{j}\right)\right|+\left|\operatorname{Imag}\left(x_{j}\right)\right|: j=1, \ldots, N\right\}$.

These functions set the result to zero and return immediately if $\mathrm{N} \leq 0$.

\section{Implementation}

In addition to the FORTRAN versions, all of the subprograms except DQDOTI and DQDOTA are also supplied in assembler language for the Univac 1108, the IBM 300/67, and the CDC 6600 and 7600. The FORTRAN versions of DQDOTI and DQDOTA use part of Brent's multiple precision package, Ref. [14]. Assembler language modules for these two subprograms are given only for the Un1vac 1108 .

Only four of the assembly routines for the CDC 6600 and 7600 take advantage of the pipeline architecture of these machines. The four routines 
$\operatorname{SDOT}(), \operatorname{SAXPY}(), \operatorname{SROT}()$, and $\operatorname{SROTM}()$ are those typically used in the innermost loop of computations. Some timing results are given in section 8 .

The subprograms SMCHCN and DMCHCN provide three machine dependent parameters that are used by the five routines SROTG, DROTG, SNRM2, DNRM2 and SCNRM2. These parameters are: SMALL $\equiv$ smallest positive floating point number, $\mathrm{BIG} \equiv$ biggest positive floating point number, and EPS $\equiv$ relative arithmetic precision. They are computed by use of subprograms SMCHAR and DMCHAR. These two subprograms were provided by W. 'T. Cndy. An individual computer installation may wish to remove Cody's routines and simply have the subprograms SMCHCN and DMCHCN return the appropriate constants. The test driver prints these numbers so that their values will be known by the user installation.

\section{Relation to the ANS FORTRAN Standard}

As of this writing (May, 1977) the present American National Standard FORTRAN is the 1966 standard, Ref. [6-8], that we will refer to as 1966 FORTRAN. A draft proposed revision to this standard is currently identified as FOR'IRAN 77, Ref. [9], presently in the final editing phase.

The calling sequences of the BLA subprograms would require that the subprograms contain declarations of the form

$$
\text { REAL } \operatorname{SX}\left(\operatorname { M A X O } \left(1, N^{*} \operatorname{IABS}(\text { INCX) })\right.\right.
$$

to precisely specify the array longths. Neither 1566 FORTRAN nor FORTRAN 77 permits such a statement. A statement of the form

$$
\text { REAL SX(1) }
$$

is permitted by major FORTRAN compilers to cover cases in which it is inconvenient to specify an exact dimension. This latter form is used in the BLA subprograms even though it does not conform to 1966 FORTRAN. FORTRAN 77 
allows the form

$$
\text { REAL } \quad \operatorname{SX}(*)
$$

for this situation. Thus the BLAS can be made to conform to FORTRAN 77 by changing "l's" to "*'s" in the subprogram array declarations.

\section{Testing}

A Master Test Package has been written in FORTRAN and is included with the submitted code. This package consists of a main program and a set of subprograms containing built-in test data and correct answers. It exécutes

a fixed set of test cases exercising all thirty-eight subprograms or optionally any selected subset of these.

The test driver also calls subroutines SMCHCN and DMCHCN and prints the values of machine dependent values determined by these subroutines. We have attempted to design the test cases and the Master Test-Program to be usable on a wide variety of non-decimal machines having FORTRAN systems.

The Master Test Package has successfully executed, testing the FORTRAN coded version of the Basic Linear Algebra Subprograms, on Univac 1108, IBM 360/67, Burroughs 6700, CDC 6600, and CDC 7600 computers. These tests have also been run successfully testing the respective assembler packages on the Univac 1108, IBM 360/67, CDC 6600 and CDC 7600 computers.

The following method of comparing true and computed numbers is used in the Master Test Package. Let $z$ denote a pre-stored true result and let $\bar{z}$ denote the corresponding computer result to be tested. The numbers $\sigma$ and $\varnothing$ are prestored constants that will be discussed below. The test program computes

$$
\begin{aligned}
& \mathrm{d}=\mathrm{fl}(\overline{\mathrm{z}-z}) \\
& \mathrm{g}=\mathrm{fl}\left(|\sigma|+\left|f l\left(\phi^{*} \mathrm{~d}\right)\right|\right) \\
& \mathrm{h}=|\sigma| \\
& \mathrm{T}^{=}=\mathrm{fl}(\mathrm{g}-\mathrm{h})
\end{aligned}
$$


where fl denotes machine floating point arithmetic of the current working precision, either single precision or double precision. It is further assumed that $g$ and $h$ are tmuncated to working precision before being used in the computation of $\tau$.

The test is passed if $\tau=0$ and fails if $\tau \neq 0$. Note that $\tau$ will be zero if $|\alpha|$ is so small that adding $\left|f l\left(\phi^{*} d\right)\right|$ to $|\sigma|$ gives a result that is not distinguished from $|\sigma|$ when truncated to working precision.

For example, suppose $\sigma-1 ., \phi-.5, \mathrm{~d}-10^{-9} ;$ Lhen the mathematical value of $\pi+\not * \pi$ is 1.0000000005 , but the single prec1sion computed value of $g$ on the Univac 1108 will be 1 . resulting in $\tau=0$. Thus in this case d is small enough to pass the test.

The number $\sigma$ is prestored along with the correct result $z$ in the testing program. In general, $\sigma$ has different values for different test cases.

The number $\varnothing$ is a "tuning" factor which has been determined empirically to make the test perform correctly on a variety of machines. Note that the stringency of the test is relaxed by decreasing the value of $\phi$. This has been used to desensitize the testing to the effects of differences in the treatment of trailing digits in the floating, point arithmetic of different machines.

There are four different values of prestores in the main program, TBLA, of the testing package. These values are called SFAC, SDFAC, DFAC, and DQFAC. These are used for testing operations which are respectively single precision, mixed single and double precision, double precision, and mixed double and extended precision.

It is intended that the test package be useful to anyone who undertakes the implementation of an assembly-coded version of this package. In working on a new machine, one may find it necessary to reduce the values of one or more of the numbers SFAC, SDFAC, DFAC, or DQFAC to obtain correct test 
performance. The authors would appreciate hearing of any new assemblycoded versions of the packages and of any need to reduce the values of these tuning parameters.

9. Selected Timing Results for the IBM 360/67, CDC 6600 and Univac 1108 Timing of Dot Products and Elementary Vector Operations

The most obvious implementation of the dot product and elementary vector operations for vectors with unit storage increments are in-line FORTRAN loops 1 and 2:

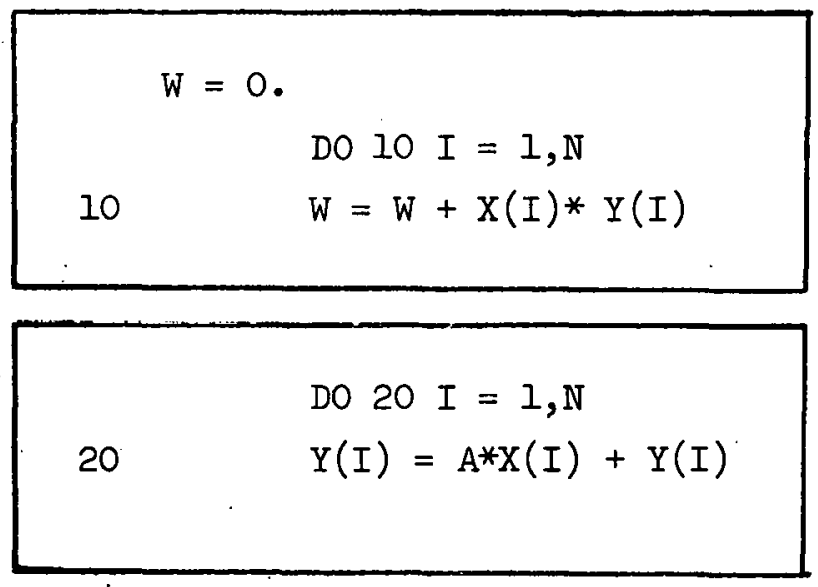

In-Line FORTRAN for Dot Products Loop 1 In-Line FORTRAN for : Elementary Vector Operations

Loop 2

The BLAS replacements for these in-line FORTRAN loops, using the same variable names and approprlate type statements, are

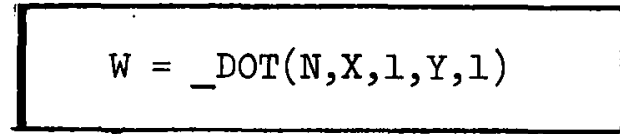

CALL_AXPY $(N, A, X, I, Y, I)$
BLAS

Replacement for Loop 1

BLAB

Replacement for Loop 2

The " " in front of the BLA subprogram names is due to the fact that both single and double precision versions are discussed here.

These subprograms, coded in assembly language, were timed and compared 
with the time for the in-line loops. As was stated in section 2, one reason for development of the package was to make highly efficient code possible. This goal has been achieved for the CDC 6600 but not for the IBM 360/67. The IBM 360/67 FORTRAN H eompiler, opcrating with Opl $\equiv$ ?, gelierales nearly perfect object, rnite.

In Tables 2 and 3 are some sample times for the three machines comparing Loops 1 and 2 and their BLAS replacement. Interpretation of Tables 2 and 3, supported more fully in Appendix 2, are as follows:

- Because of Iinkage overhead, the BLA subprograms for the IBM $360 / 67$ are always less efficient than the in-line loops. For vectors of large enough length the linkage overhead is relatively negligible.

- The dot product and elementary vector operation subprograms for the CDC 6600 are respectively 3.1 and 1.6 times more efficient than in-line code for vectors of large enough length.

- For the CDC 6600 , dot products are considerably more efficient than elementary vector operations on vectors of the same length. 


\begin{tabular}{|c|c|c|c|c|c|c|}
\hline $\begin{array}{l}\text { Vector } \\
\text { Length, } \\
\text { N }\end{array}$ & $\begin{array}{r}\text { IBM } \\
\text { Double } \\
\text { In-Line } \\
\text { FORTRAN } \\
(\mathrm{H}, \text { Opt }=2) \\
\end{array}$ & $\begin{array}{l}60 / 67 \\
\text { recision } \\
\text { Assembler }\end{array}$ & $\begin{array}{r}\text { CDC } \\
\text { Single } \\
\text { In-Line } \\
\text { FORTRAN } \\
(\text { FTN,Opt }=2)\end{array}$ & $\begin{array}{l}6600 \\
\text { recision }\end{array}$ & $\begin{array}{r}\text { Univ } \\
\text { Single } \\
\text { In-Line } \\
\text { FORTRAN }\end{array}$ & $\begin{array}{l}1108 \\
\text { recision }\end{array}$ \\
\hline 10 & 0.1438 & 0.1917 & 0.0360 & 0.0480 & 0.0756 & 0.0790 \\
\hline 25 & 0.3436 & 0.3854 & 0.0750 & 0.0625 & 0.1836 & 0.1730 \\
\hline 50 & 0.6719 & 0.7186 & 0.1400 & 0.0800 & 0.3598 & 0.3182 \\
\hline 100 & 1.3750 & 1.3750 & 0.2800 & 0.1250 & 0.6986 & 0.6162 \\
\hline \multicolumn{7}{|c|}{$\begin{array}{l}\text { Time, in seconds, for } 1000 \text { executions of in-line FORTRAN Loop } 1 \text { and calls to } \\
\text { the _DOT( ) function. Times for } 5 \text { runs were averaged. } \\
\text { Apply factors of } 1.1 \text { and } 0.75 \text { to IBM } 360 / 67 \text { times to get approximate respective } \\
\text { times for nonequally spaced increments and single precision. No distinction for } \\
\text { nonequal increments is necessary for the CDC } 6600 \text { and Univac } 1108 \text {. }\end{array}$} \\
\hline
\end{tabular}

Table 2. _ DOT( ) function and in-line Loop I timings

\begin{tabular}{|c|c|c|c|c|c|c|}
\hline $\begin{array}{l}\text { Vector } \\
\text { Length, } \\
\text { N }\end{array}$ & $\begin{array}{r}\text { IBM } \\
\text { Double } \\
\text { In-Iine } \\
\text { FORTRAN } \\
(\mathrm{H}, \text { Opt=2) }\end{array}$ & $\begin{array}{l}60 / 67 \\
\text { recision } \\
\text { Assembler }\end{array}$ & $\begin{array}{r}\text { CDC } \\
\text { Single } \\
\text { In-Line } \\
\text { FORTRAN } \\
\text { (FTN, Opt=2) }\end{array}$ & $\begin{array}{l}6600 \\
\text { recision } \\
\text { Assembler }\end{array}$ & $\begin{array}{r}\text { Univ } \\
\text { Single } \\
\text { In-Line } \\
\text { FORTRAN }\end{array}$ & $\begin{array}{l}1108 \\
\text { recision } \\
\text { Assembler }\end{array}$ \\
\hline 10 & 0.0590 & 0.2050 & 0.0500 & 0.0650 & 0.0740 & 0.0886 \\
\hline 25 & 0.3930 & 0.4375 & 0.1125 & 0.1000 & 0.1806 & 0.1890 \\
\hline 50 & 0.7950 & 0.8400 & 0.2100 & 0.1725 & 0.3544 & 0.3574 \\
\hline 100 & 1.5500 & 1.6000 & 0.4200 & 0.3000 & 0.7292 & 0.7170 \\
\hline $\begin{array}{l}\text { Time, in } \\
\text { _AXPY ( ) } \\
\text { Apply } f \\
\text { with un }\end{array}$ & $\begin{array}{l}\text { conds, for } \\
\text { ibprogram. } \\
\text { or of } 0.75 \\
\text { increments }\end{array}$ & $\begin{array}{l}\text { oo execut } \\
\text { mes for } 5 \\
\text { get singl } \\
\text { re used ir }\end{array}$ & $\begin{array}{l}\text { ons of in-li } \\
\text { uns were av } \\
\text { precision } \\
\text { this timing }\end{array}$ & $\begin{array}{l}\text { re FORTRAN } \\
\text { raged. } \\
\text { BM } 360 / 67\end{array}$ & $\begin{array}{l}\mathrm{p} 2 \text { and } \\
\text { s. Only }\end{array}$ & $\begin{array}{l}\text { Is to the } \\
\text { etors }\end{array}$ \\
\hline
\end{tabular}

Table 3. _AXPY( ) subprogram and in-line Loop 2 timings 


\section{Timing of Standard and Modified Givens Methods}

Gentlemen's modification of the Givens transformation is discussed in the Appendix. This technique eliminates square roots and two of the four multiply : operations when forming the product of the resulting matrix by a 2-vector.

The relative efficiency of Gentlemen's modification to the standard Givens transformation was compared. Both techniques were usen ton triangularize $2 \mathrm{~N}$ by $\mathrm{N}$ matrices $A=\left\{a_{j . j}\right\}$ where

$$
a_{i j}=(i+j-1)^{-1}
$$

In Table 4 there are some sample times which resulted from the triangularizations using both methods.

We are primarily interested in algorithm comparison here, so both methods were timed using their assembler versions to apply the matrix products.

A conclusion is that in the context of triangularizing matrices, the modified Givens transformation method is ultimately more efficient in computer time by factors varying between 1.4 and 1.6. This is fully supported in Appendix 2. The comparison is most favorable on the IBM $360 / 67$ in double precision. 


\begin{tabular}{|c|c|c|c|c|c|c|}
\hline $\mathrm{N}$ & \multicolumn{2}{|c|}{$\begin{array}{cl}\text { IBM } & 360 / 67 \\
\text { Double Precision }\end{array}$} & \multicolumn{2}{|c|}{$\begin{array}{c}\text { CDC } 6600 \\
\text { Single Precision }\end{array}$} & \multicolumn{2}{|c|}{$\begin{array}{l}\text { Univac } 1108 \\
\text { Single Precision }\end{array}$} \\
\hline $\begin{array}{l}10 \\
25\end{array}$ & $\begin{array}{l}0.0800 \\
0.8789\end{array}$ & $\begin{array}{l}0.0650 \\
0.6250\end{array}$ & $\begin{array}{l}0.0200 \\
0.1719\end{array}$ & $\begin{array}{l}0.0190 \\
0.1445\end{array}$ & $\begin{array}{l}0.0335 \\
0.3633\end{array}$ & $\begin{array}{l}0.0298 \\
0.3001\end{array}$ \\
\hline $\begin{array}{l}\mathrm{Ti} \\
\text { an }\end{array}$ & $\begin{array}{l}\text { conds, } f \\
\text { d Givens }\end{array}$ & forma & $\begin{array}{l}\text { arizatio } \\
\text {. Time }\end{array}$ & $\begin{array}{l}\text { IN by } \mathrm{N} \\
5 \text { muns }\end{array}$ & $\begin{array}{l}\text { ices } u \\
\text { avera }\end{array}$ & ard \\
\hline
\end{tabular}

Table 4. Standard and modified Givens transformation in matrix triangularization

\section{Acknowledgements}

We are grateful for the contributions that numerous people have made to this project. The Master Test Package was programmed by Lawson, with a few modifications by Hanson. The FORTRAN versions of the BLA subprograms were written by Lawson, Krogh, Hanson, and J. Dongarra. The assembly-coded versions for the Inivac 1108 were programmed by Krogh and S. Singletary Gold. The assembly-coded versions for the IBM 360/67 were programmed by Hanson and K. Haskell. The assembly-coded versions for the CDC 6600 were programmed by Kincaid, J. Sullivan and E. Williams. Four of these routines were recoded by Hanson and C. Moler. Test muns were made on a variety of machines by P. Fox and E. W. McMahon (Honeywell 6000), P. Knowlton (PDP 10), L. Fosdick (CDC 6600), C. Moler (IBM 360/67), K. Fong (CDC 7600), B. Garbow, J. Dongarra (IBM 370/195), W. Brainerd (Burroughs 6700), and others. Helpful suggestions, based on previous similar work of their own, were given by P. S. Jensen and C. Balley. J. Dongarra supplied versions of several FORTRAN implementations of 
the subprograms. The choice of coding technique used by Dongarra is based on a set of tests that was carried out at over 40 different installations with various machines in operation. The choice of coding technique was made on the basis of superior timing performance at the largest number of these sites, Ref. [10].

Not everyone who contributed significantly to this project is mentioned. One person who spent a great deal of time during the final phase of the project was $\mathrm{J}$. Wisniewski. His valuable help and contributions are much appreciated. The contributions of W. MacGregor and G. Terrell are also acknowledged.

\section{References}

1. R. J. Hanson, F. T. Krogh, and C. L. Lawson, "A Proposal for Standard Linear Algebra Subprograms," Jet Propulsion Laboratory, TM 33-660, November 1973, $14 \mathrm{pp}$.

2. C. L. Lawson, "Standardization of FORTRAN Callable Subprograms for Basic Linear Algebra," Paper presented at Mathematical Software II, Purdue University, May 1974, $8 \mathrm{pp}$.

3. W. M. Gentleman, "Least Squares Computations by Givens Transformations without Square Roots," J. Inst. Math. Appl., 12, 1973, pp. 329-336.

4. Sven Hammarling, "A Note on Modifications of the Givens Plane Rotation," J. Inst. Math. Appl., 13, 1974, No. 2, pp. 215-218.

5. C. L. Lawson and R. J. Hanson, Solving Least Squares Problems, Prentice-Hall, 1974.

6. American National Standards Institute, "American National Standard FORTILAN," IgeE, New Yurk.

7. ASA Committee X3 "FORTRAN vs. Basic FORTRAN," Comm. ACM, 7, No. 10, $1964,591-625$.

8. ANSI Subcommittee X3J3, "Clarification of FORTRAN Standards - Second Report," Comm. ACM, 14, No. 10, 1971, 628-642.

9. ANS Committee X3J3, Document X3J3/76.7 Fortran 77, March 18, 1977.

10. Dongarra, J. J., Fortran BLAS Timing. IINPACK Working Note \#3. Argonne Natl. Lab. (Draft of March, 1977) 
11. Cody, W: J., Software for the Elementary Functions. Mathematical Software, Edited by J. R. Rice. Academic Press, New York (1971).

12. Blue, J. I., A Portable Fortran Program to Find the Euclidean Norm of a Vector. Trans. Math. Software (to appear).

13. Stewart, G. W., The Economical Storage of Plane Rotations. Numer. Math., Vol. 25, No. 2, p. $137-139$ (1976).

14. Brent, R., A Fortran Multiple Precision Arithmetic Package. To appear, TOMS.

\section{Appendix 1}

The Modified Givens Transformation

The Givens transformation which eliminates $z_{1}$, if $z_{1} \neq 0$, is

$$
G W=\left(\begin{array}{cc}
c & s \\
-s & c
\end{array}\right)\left[\begin{array}{c}
w_{1} \ldots w_{N} \\
z_{1} \ldots z_{N}
\end{array}\right]
$$

where $c=w_{1} / r, s=z_{1} / r, r= \pm\left(w_{1}^{2}+z_{1}^{2}\right)^{\frac{1}{2}}$. This requires $\sim 4 N$ floating point multiplications, $2 \mathrm{~N}$ floating point additions and one square root. Gentleman, Ref. [3], has reported on a modification to the Givens transformation which reduces this operation count. Gentleman's idea is presented here in a slightly different form than found in his paper. Suppose that $\mathrm{W}$ in $\mathrm{Eq} .(\mathrm{A} . \mathrm{I})$ is available in factored form

$$
W=D^{\frac{1}{2}} X \equiv\left[\begin{array}{cc}
d_{1}^{\frac{1}{2}} & 0 \\
0 & d_{2}^{\frac{1}{2}}
\end{array}\right]\left[\begin{array}{l}
x_{1} \ldots x_{N} \\
y_{\perp} \ldots y_{N N}
\end{array}\right]
$$


Substituting $D^{\frac{1}{2}} \mathrm{X}$ for $\mathrm{W}$ and refactoring $G D^{\frac{1}{2}}$ as $\widetilde{D}^{\frac{1}{2}} \mathrm{H}$ yields

$$
G W=G D^{\frac{1}{2}} X=\widetilde{D}^{\frac{1}{2}} H X\left[\begin{array}{cc}
\widetilde{d}_{1}^{\frac{1}{2}} & 0 \\
0 & \widetilde{d}_{2}^{\frac{1}{2}}
\end{array}\right] H X
$$

The right-hand side of $\mathrm{Eq}$. (A.3) yields an updated factored form for the matrix product $G W$. The crucial point is that the matrix $H$ is selected so that two elements are exactly units. This eliminates 2N floating point multiplications when forming the matrix product $H X$. To preserve numerical stability two cases are considered:

For $|s|<|c|$

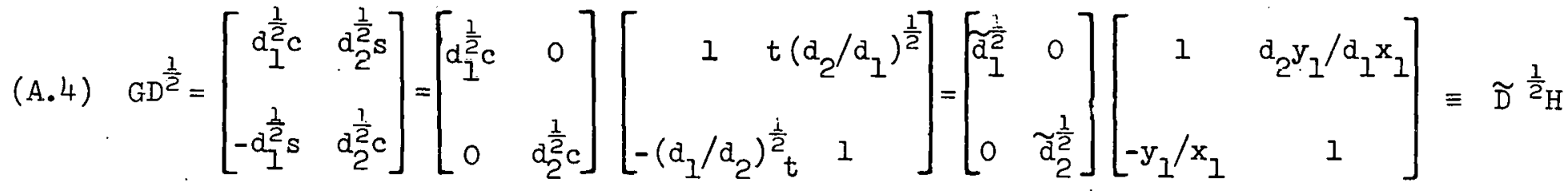
where $t=s / c$.

For $|c| \leq|s|$, by similar manipulations,

$$
G D^{\frac{1}{2}}=\left[\begin{array}{cc}
\widetilde{d}_{1}^{\frac{1}{2}} & 0 \\
0 & \widetilde{a}_{2}^{\frac{1}{2}}
\end{array}\right]\left[\begin{array}{cc}
a_{1} x_{1} / d_{2} y_{1} & 1 \\
-1 & x_{1} / y_{1}
\end{array}\right]=\widetilde{D}^{\frac{1}{2}} H
$$

where $\widetilde{d}_{1}^{\frac{1}{2}}=d_{2}^{\frac{1}{2}} s$, and $\frac{d^{\frac{1}{2}}}{2}=d_{1}^{\frac{1}{2}} s$. This factorization can be done for any plane rotation matrix.

Only the squares of the scale factors $d_{i}^{\frac{1}{2}}$ are involved in the non-unit elements of the matrix $\mathrm{H}$ defined in Eq. (A.4) - (A.5), which permits the Givens transformation Eq. (A.I) to be computed without square roots. Using the identity $c^{2}=\left(1+t^{2}\right)^{-1}$ and Eq. (A.4) allows the squares of the scale 
factors to be updated: $\widetilde{d}_{i}=d_{i}\left(1+t^{2}\right)^{-1}, i=1,2$. Letting $\tau=s / c$ in Eq. (A.5) we have $\widetilde{d}_{1}=d_{2}\left(1+\tau^{2}\right)^{-1}$ and $\widetilde{d}_{2}=d_{1}\left(1+\tau^{2}\right)^{-1}$. For $|c|>|s|$ or, equivalently, $\left|\mathrm{d}_{1} \mathrm{x}_{1}^{2}\right|>\left|\mathrm{d}_{2} \mathrm{y}_{1}^{2}\right|$

(A.6)

$$
\begin{aligned}
\mathrm{h}_{11} & =1, \mathrm{~h}_{21}=-\mathrm{y}_{1} / \mathrm{x}_{1} \\
\mathrm{~h}_{12} & =\mathrm{d}_{2} \mathrm{y}_{1} / \mathrm{d}_{11} \mathrm{x}_{1}, \mathrm{~h}_{22}=1 \\
\mathrm{u} & =1-\mathrm{h}_{21} \mathrm{~h}_{12}
\end{aligned}
$$

$$
\begin{aligned}
& d_{1}:=d_{1} / u \\
& d_{2}:=d_{2} / u \\
& x_{1}:=x_{1} u
\end{aligned}
$$

For $|c| \leq|s|$ or, equivalently, $\left|\mathrm{d}_{1} \mathrm{x}_{1}^{2}\right| \leq\left|\mathrm{d}_{2} \mathrm{y}_{1}^{2}\right|$

$$
\begin{aligned}
h_{11} & =d_{1} x_{1} / d_{2} y_{1}, h_{21}=1 \\
h_{12} & =1, h_{22}=x_{1} / y_{1} \\
u & =1+h_{11} h_{22} \\
v & =d_{1} / u \\
d_{1} & :=d_{2} / u \\
d_{2} & :=v \\
x_{1} & :=y_{1} u
\end{aligned}
$$

When using the modified Givens transformation in the context of "row accumulation," $d_{i}>0, i=1,2$, the values of $u$ in Eq. (A.6) - (A.7) will satisfy $1 \leq u \leq 2$. Thus the squares $d_{i}, i=1,2$, decrease by as much as $1 / 2$ at each updating step. If no rescaling action is taken, these scale 
factors would ultimately underflow. The details concerning rescaling are implemented in the modified Givens subprograms.

Since only $d_{i}$, the squares of the weights, appear in the formulas of Eq. (A.6) - (A.7) it is possible to use the same formulas to remove a row from a least squares problem simply by setting $\mathrm{d}_{2}=-1$. Remarks about this row removal method are found in Ref. [5], Chapter 27.

When the modified Givens transformation is used in the context of the "row removal method" mentioned above, the values of $u$ in Eq. (A.6) - (A.7) satisfy $0 \leq u \leq 1$. The case $u=0$ is eliminated by restricting $d_{1} \geq 0$. If $\mathrm{d}_{1}<0$, we define $\mathrm{H}$ as the zero matrix, the updated $\mathrm{d}_{i}=0, i=1,2$, and $\mathrm{x}_{1}=0$. With this restriction, we have $0<u \leq 2$ in Eq. (A.6) - (A.7). Thus the change in the scale factors $d_{i}, i=1,2$, is unbounded at each step. Either underflow or overflow can occur if no rescaling is performed.

The problem is rescaled by the modified Givens subprograms to keep within the conservative limits

$$
\gamma^{-2} \leq\left|d_{i}\right| \leq \gamma^{2}, \quad i=1,2, v=4096
$$

Note that when we rescale $d_{i}:=d_{i} \gamma^{2}$, we must rescale $h_{i, j}:=h_{i, j} \gamma^{-1}$, $j=1,2$, and rescale $x_{1}:=x_{1} \gamma^{-1}$. 


\section{Appendix 2}

Extended Timing Results for Some Operations

In Section 9 selected timing results were presented for the IBM 360/67 (double precision), the CDC 6600 (single precision), and the Univac 1108 (single precision). Timing of dot products, elementary vector operations, and Givens transformations was presented. This was done mainly for the purpose of illustrating the relative efficiency of in-line FORTRAN vs: assembler, and the standard vs。 the modified Givens transformation.

Tables 5-11, given below, give more of this data than found in Section 9. The exception to this is the Univac 1108 timing data which is totally presented in Section 9 , so we did not reproduce it here.

\begin{tabular}{|c|c|c|c|c|}
\hline $\begin{array}{l}\text { Vector } \\
\text { Length, } \\
\quad \mathrm{N}\end{array}$ & \multicolumn{2}{|c|}{$\begin{array}{cl}\text { IBM } & 360 / 67 \\
\text { Single } & \text { Precision }\end{array}$} & \multicolumn{2}{|c|}{$\begin{array}{c}\text { IBM } 360 / 67 \\
\text { Single Precision } \\
\text { Nonequal Storage Increments }\end{array}$} \\
\hline . & $\begin{array}{l}\text { In-Iine } \\
\text { FORTRAN } \\
(\mathrm{H}, \text { Opt }=2)\end{array}$ & Assembler & $\begin{array}{l}\text { In-Line } \\
\text { FORTRAN } \\
(\mathrm{H}, \text { Opt=2) }\end{array}$ & Assembler \\
\hline 10 & 0.1020 & 0.1470 & $0.116^{\circ}$ & U.1650 \\
\hline 25 & 0.2380 & 0.2840 & 0.2740 & 0.3100 \\
\hline 50 & 0.4620 & 0.5110 & 0.5510 & 0.5720 \\
\hline 100 & 0.9490 & 0.9970 & 1.1700 & 1.1000 \\
\hline $\begin{array}{l}\text { Time, } i \\
\text { Section } \\
\text { were av }\end{array}$ & $\begin{array}{l}\text { conds, fo: } \\
\text { and calls } \\
\text { ed. }\end{array}$ & $\begin{array}{l}000 \text { exe } \\
\text { the SD }\end{array}$ & $\begin{array}{l}\text { in-lin } \\
\text { ion. }\end{array}$ & $\begin{array}{l}\text { RAN Loop } 1, \\
\text { Cor } 5 \text { runs }\end{array}$ \\
\hline
\end{tabular}

Table 5. IBM $360 / 67 \operatorname{SDOT}()$ function and single precision in-line Loop 1 timings 


\begin{tabular}{|c|c|c|c|c|}
\hline \multirow[t]{2}{*}{$\begin{array}{l}\text { Vector } \\
\text { Length, } \\
\mathrm{N}\end{array}$} & \multicolumn{2}{|c|}{$\begin{array}{l}\text { IBM } 360 / 67 \\
\text { Double Precision } \\
\text { Equal Storage Increments }\end{array}$} & \multicolumn{2}{|c|}{$\begin{array}{c}\text { IBM } 360 / 67 \\
\text { Double Precision } \\
\text { Nonequal Storage Increments }\end{array}$} \\
\hline & $\begin{array}{l}\text { In-Iine } \\
\text { FORTRAN } \\
(\mathrm{H}, \text { Opt }=2)\end{array}$ & As sembler & $\begin{array}{l}\text { In-Line } \\
\text { FORTRAN } \\
(\mathrm{H}, \text { Opt=2) }\end{array}$ & Assembler \\
\hline 10 & 0.1430 & 0.1910 & 0.1590 & 0.1980 \\
\hline 25 & 0.3430 & 0.3840 & 0.3840 & 0.4160 \\
\hline 50 & 0.6770 & 0.7250 & 0.7800 & 0.8180 \\
\hline 100 & 0.3900 & J. 3900 & 1.5400 & 1.5700 \\
\hline \multicolumn{5}{|c|}{$\begin{array}{l}\text { Time, in seconds, for } 1000 \text { executions of in-line FORTRAN Loop } 1 \text {, } \\
\text { Section } 9 \text {, and calls to the DDOT( ) function. Times for } 5 \text { mus were } \\
\text { averaged. }\end{array}$} \\
\hline
\end{tabular}

Table 6. IBM 360/67 DDOT( ) function and double precision in-line Loop 1 timings

\begin{tabular}{|c|c|c|c|c|}
\hline \multirow[t]{2}{*}{$\begin{array}{l}\text { Vector } \\
\text { Length, } \\
\quad \mathrm{N}\end{array}$} & \multicolumn{2}{|c|}{$\begin{array}{l}\text { CDC } 6600 \\
\text { Single Precision Equal or } \\
\text { Nonequal Storage Increments }\end{array}$} & \multicolumn{2}{|c|}{$\begin{array}{l}\text { Cnc } 7600 \\
\text { Single Precision Equal or } \\
\text { Nonequal Storage Increments }\end{array}$} \\
\hline & $\begin{array}{l}\text { In-Iine } \\
\text { FORTRAN } \\
(\text { FTN, Opt=2) }\end{array}$ & Assembler & $\begin{array}{l}\text { In-Line } \\
\text { FORTRAN } \\
(\text { FTN, Opt=2) }\end{array}$ & Assembler \\
\hline 10 & 0.0358 & 0.0480 & 0.0042 & 0.0092 \\
\hline 25 & 0.0756 & 0.0638 & 0.0100 & 0.0110 \\
\hline 50 & 0.1420 & 0.0808 & 0.0210 & $0.016 ?$ \\
\hline 100 & 0.2750 & 0.1230 & 0.0414 & 0.0254 \\
\hline \multicolumn{5}{|c|}{$\begin{array}{l}\text { Time, in seconds, for } 1000 \text { executions of in-line FORTRAN Loop } 1 \text {, } \\
\text { Section } 9 \text {, and calls to the } \operatorname{SDOT}(\text { ) function. Times for } 5 \text { runs were } \\
\text { averaged. }\end{array}$} \\
\hline
\end{tabular}

Table 7. CDC 6600 and $\operatorname{CDC} 7600 \operatorname{SDOT}($ ) function and single precision in-line Loop 1 timings 


\begin{tabular}{|c|c|c|c|c|}
\hline \multirow[t]{2}{*}{$\begin{array}{l}\text { Vector } \\
\text { Length, } \\
\quad \mathrm{N}\end{array}$} & \multicolumn{2}{|c|}{$\begin{array}{c}\text { IBM } 360 / 67 \\
\text { Single Precision } \\
\text { Equal Storage Increments }\end{array}$} & \multicolumn{2}{|c|}{$\begin{array}{c}\text { IBM } 360 / 67 \\
\text { Double Precision } \\
\text { Equal Storage Increments }\end{array}$} \\
\hline & $\begin{array}{l}\text { In-Line } \\
\text { FORTRAN } \\
(\mathrm{H}, \text { Opt }=2)\end{array}$ & Assembler & $\begin{array}{l}\text { In-Line } \\
\text { FORTRAN } \\
(\mathrm{H}, \text { Opt }=2)\end{array}$ & As sembler \\
\hline 10 & 0.1190 & 0.1700 & 0.1590 & 0.2040 \\
\hline 25 & 0.2880 & 0.3610 & 0.3930 & 0.4390 \\
\hline 50 & 0.5760 & 0.6300 & 0.7960 & 0.8420 \\
\hline 100 & 1.1700 & 1.1900 & 1.5500 & 1.5900 \\
\hline
\end{tabular}

Table 8. IBM 360/67 SAXPY( ) and DAXPY( ) subprogram, and single and double precision in-line Loop 2 timings

\begin{tabular}{|c|c|c|c|c|}
\hline \multirow[t]{2}{*}{$\begin{array}{l}\text { Vector } \\
\text { Length, } \\
\quad \mathrm{N}\end{array}$} & \multicolumn{2}{|c|}{$\begin{array}{l}\text { CDC } 6600 \\
\text { Single Precision } \\
\text { Equal Storage Increments }\end{array}$} & \multicolumn{2}{|c|}{$\begin{array}{l}\text { CDC } 7600 \\
\text { Single Precision } \\
\text { Equal Storage Increments }\end{array}$} \\
\hline & $\begin{array}{l}\text { In-Line } \\
\text { FORTRAN } \\
(\text { FTN, Opt }-2)\end{array}$ & Assembler & $\begin{array}{l}\text { In-Line } \\
\text { FORTRAN } \\
(\text { FTN, Ont:=?) }\end{array}$ & As sembler \\
\hline 10 & 0.0502 & 0.0640 & 0.0060 & 0.0114 \\
\hline 25 & 0.1120 & 0.1020 & 0.0150 & 0.0162 \\
\hline 50 & 0.2130 & 0.1710 & 0.0290 & 0.0252 \\
\hline 100 & 0.4240 & 0.3020 & 0.0582 & $0.04 ? 0$ \\
\hline \multicolumn{5}{|c|}{$\begin{array}{l}\text { Time, in seconds, for } 1000 \text { executions of in-line FORTRAN Loop } 2 \text {, } \\
\text { Section } 9 \text {, and calls to the SAXPY( ) subprogram. Times for } 5 \\
\text { muns were averaged. }\end{array}$} \\
\hline
\end{tabular}

'l'able 9. CDC 6600 and CDC 7600 SAXPY( ) subprogram and oingle precision in-line Loop 2 timings 


\begin{tabular}{|c||c|c||cc|}
\hline$N$ & \multicolumn{2}{|c|}{$\begin{array}{c}\text { IBM } \\
\text { Single }\end{array}$} & Precision & \multicolumn{2}{|c|}{$\begin{array}{c}\text { IBM } 360 / 67 \\
\text { Double Precision }\end{array}$} \\
\cline { 2 - 5 } & $\begin{array}{c}\text { Standard } \\
\text { Givens }\end{array}$ & $\begin{array}{c}\text { Modified } \\
\text { Givens }\end{array}$ & $\begin{array}{c}\text { Standard } \\
\text { Givens }\end{array}$ & $\begin{array}{c}\text { Modified } \\
\text { Givens }\end{array}$ \\
\hline 10 & 0.0580 & 0.0484 & 0.0800 & 0.0650 \\
25 & 0.5850 & 0.4635 & 0.8789 & 0.6250 \\
\hline
\end{tabular}

Time, in seconds, for the triangularization of $2 \mathrm{~N}$ by $N$ matrices using standard and modified Givens transformations. Times for 5 runs were averaged.

Table 10. IBM 360/67 single and double precision standard and modified Givens transformation timing for matrix triangularization

\begin{tabular}{|c|c|c|c|c|}
\hline \multirow[t]{2}{*}{$N$} & \multicolumn{2}{|c|}{$\begin{array}{c}\text { CDC } 6600 \\
\text { Single Precision }\end{array}$} & \multicolumn{2}{|c|}{$\begin{array}{l}\text { CDC } 7600 \\
\text { Single Precision }\end{array}$} \\
\hline & $\begin{array}{l}\text { Standard } \\
\text { Givens }\end{array}$ & $\begin{array}{l}\text { Modified } \\
\text { Givens }\end{array}$ & $\begin{array}{l}\text { Standard } \\
\text { Givens }\end{array}$ & $\begin{array}{l}\text { Modified } \\
\text { Givens }\end{array}$ \\
\hline 10 & 0.0200 & 0.0190 & 0.0036 & 0.0035 \\
\hline 25 & 0.1719 & 0.14 .45 & 0.0279 & 0.0250 \\
\hline 50 & 0.9600 & 0.7550 & 0.1430 & 0.1265 \\
\hline 100 & 5.8500 & 4.3500 & 0.8200 & 0.7100 \\
\hline \multicolumn{5}{|c|}{$\begin{array}{l}\text { Time, in seconds, for the triangularization of } 2 \mathrm{~N} \\
\text { by } \mathrm{N} \text { matrices using standard and modified Givens } \\
\text { transformations. Times for } 5 \text { runs were averaged. }\end{array}$} \\
\hline
\end{tabular}

Table 11. CDC 6600 and CDC 7600 single precision standard and modified Givens transformation timing for matrix triangularization 


\section{Appendix 3}

Sample Usage of the BLAS in FORTRAN Programming

Our experience indicates that using the BLAS actually enhances the readability and reliability of codes in which they are utilized. Efficiency does not appreciably degrade with their usage, as indicated in Section 9, and for large-scale problems certain of the BLAS will markedly out-perform in-line FORTRAN code.

These remarks are based on usage of the BLAS in developing new software for the Sandia Math. Library, developing new ordinary differential equation solving codes, conversations with members of the LINPACK working group participating in the project of Ref. [10], and experience with applications programmers at Sandia Laboratories and Jet Propulsion Laboratory。

Typical usage of the BLAS in FORTRAN programs is now illustrated with nine examples using the single precision versions of the operations.

Some rules, based upon the FORTRAN language, that a programmer may find useful to recall are these:

- Suppose a two-dimensional FORTRAN array A(MDA, NDA) is used to hold an M by $N$ matrix $A=\left\{a_{I J}\right\}$. If $A(I, J):=a_{I J}$, then the Ith row vector of $A$ and the Jth column vector of $A$ respectively start at $A(I, I)$ and $A(I, J)$. The relations $M D A \geq M$ and $N D A \geq N$ must hold for the matrix to fit into this array.

- The storage increment between elements of row vectors of $A, e . g . A(I, 1)$ and $A(1,2)$, is $M D A$, the first dimensioning parameter of the array $A(*, *)$.

- The storagc increment between elements of column vectors of $A$, e.g. $A(1,1)$ and $A(2,1)$, is 1 . This is due to the fact that the FORTRAN language stores $A(*, *)$ by columns:

$$
A(1,1), A(2,1), \ldots, A(M D A, 1), A(1,2), \ldots, A(M D A, 2), \ldots, A(M D A, N D A)
$$

The value of NDA is used by the FORTRAN compiler only to allocate MDA*NDA words of memory in the program. 
Example 1

Given $M$ by $K$ and $K$ by $N$ matrices $A$ and $B$, compute the $M$ by $N$ product matrix $C=A B$.

The coding technique for this computation is based on the fact that each element $c_{I J}$ of $C$ is the dot product of row $I$ of $A$ and column $J$ of $B$.

$\mathrm{C}$

DIMENSION $A(20,20), B(15,10), C(20,15)$

$M T A=P \cap$

$M . D B=15$

$\mathrm{MDC}=20$

C,

$M=10$

$\mathrm{K}=15$

$\mathrm{N}=10$

$\mathrm{C}$

C FORM THE DOT PRODUCT OF ROW I OF A WITH COLUMN J OF B. EACH OF THESE

C VECTORS IS OF LENGTH $\mathrm{K}$. THE VALUE OF MDA IS THE STORAGE INCREMENT

C BETWEEN ELEMENTS OF ROW VECTORS OF A.

C

10

$$
\begin{aligned}
& \text { DO } 10 I=I, M \\
& \text { DO I0 J=I,N } \\
& C(I, J)=\operatorname{SDOT}(K, A(I, I), \operatorname{MDA}, B(I, J), I)
\end{aligned}
$$

\section{Example 2}

Solve an $\mathrm{N}$ by $\mathrm{N}$ upper triangular nonsingular system of algebraic equations, $A \underset{\sim}{A}=\underline{b}$. The method used is based on the observation that if we compute the component $\mathrm{x}_{\mathrm{N}}=\mathrm{b}_{\mathrm{N}} / \mathrm{a}_{\mathrm{NN}}$, then we have a new problem in $\mathrm{N}-1$ unknowns, still upper triangular, with the new right-side vector $\left(b_{1}-a_{1 N} x_{N}, \ldots, b_{N-1}-a_{N-1, N} x_{N}\right)^{T}$. In this example the solution vector, $x$, overwrites the vector $\underline{b}$ in the array $B(*)$.

20

$$
\begin{aligned}
& \text { DO } 20 \quad I I=1, N \\
& I=N+I-I I \\
& B(I)=B(I) / A(I, I) \\
& \text { CAIL SAXPY }(I-I,-B(I), A(I, I), I, B, I)
\end{aligned}
$$




\section{Example 3}

Scale the columns (each assumed to be nonzero) of an $M$ by $N$ matrix $C$ so that each column has unit length.

30

DO $30 \mathrm{~J}=1, \mathrm{~N}$

$\mathrm{T}=1 . \mathrm{EO} / \operatorname{SNRM} 2(\mathrm{M}, \mathrm{C}(1, \mathrm{~J}), 1)$

CALL $\operatorname{SSCAL}(\mathrm{M}, \mathrm{T}, \mathrm{C}(1, \mathrm{~J}), \mathrm{I})$

Example 4

Row-equilibrate an $\mathrm{N}$ by $\mathrm{N}$ matrix $\mathrm{A}$. (Divide each non-zero row vector of: $A$ by the entry in that row of maximum magnitude). Here MDA is the first dimensioning parameter of the array $A(*, *)$.

40

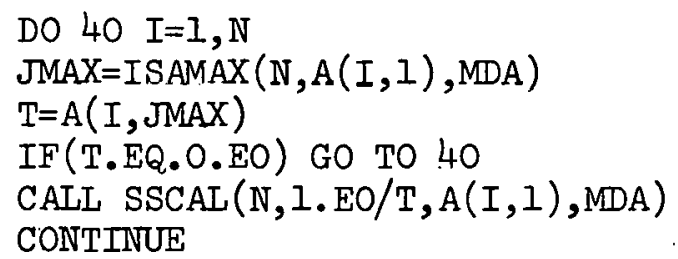

When using ISAMAX( ) to choose row pivots in Gaussian elimination, for example, the major loop contains a statement of the form

$$
\operatorname{IMAX}=\operatorname{ISAMAX}(\mathrm{N}-\mathrm{J}+\mathrm{I}, \mathrm{A}(\mathrm{J}, \mathrm{J}), \mathrm{I})+\mathrm{J}-\mathrm{I}
$$

At that point IMAX corresponds to the row that will be interchanged with row $J$. Thus the offset value $J-1$ must be added to the computed value of ISAMAX( ) to get the actual row number to interchange.

\section{Example 5}

Set an $N$ by $N$ matrix $A$ to the $N$ by $N$ identity matrix. Then set $B=A$. Notice that a storage increment value of 0 for the first vector 
argument of SCOPY( ) is used. This "broadcasts" the values of O.EO and

1.EO into the second vector argument.

Here MDA is the first dimensioning parameter of the array $A(*, *)$.

50

DO $50 \mathrm{~J}=1, \mathrm{~N}$

$\operatorname{CALL} \operatorname{SCOPY}(\mathbb{N}, O . E O, O, A(1, J), 1)$

$\operatorname{CALL} \operatorname{SCOPY}(\mathrm{N}, 1 . E O, O, A, M D A+I)$

60

DO $60 \mathrm{~J}=1, \mathrm{~N}$

CALL $3 \operatorname{COPY}(N, A(I, J), I, B(I, J), . \perp)$

Example 6

Interchange or swap the columns of an $\mathrm{M}$ by $\mathrm{N}$ matrix $\mathrm{C}$. The column to be interchanged with column $J$ is in a type INTEGER array IP(*), and has the value $\operatorname{IP}(J)$.

70

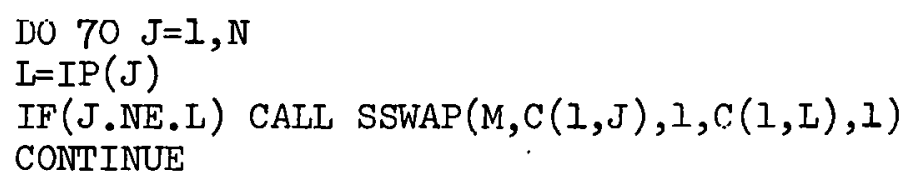

\section{Example 7}

a) Extract the first number and "pop" a list of $N$ single precision numbers: $x_{0}:=x_{1}, x_{i}:=x_{i+1}, i=1, \ldots, N-1, N:=N-1$

b) "Push-down" a list of $\mathrm{N}$ single precision numbers and insert a new number $x_{0}$ at the top of the list: $x_{i+1}:=x_{i}, i=N, \ldots, I$; $\mathrm{x}_{1}:=\mathrm{x}_{0}, \mathrm{~N}:=\mathrm{N}+\mathrm{I}$.

For these illustrations the vector $x=\left(x_{1}, \ldots, x_{N}\right)^{T}$ is in the FORTRAN $\operatorname{array} \mathrm{X}(*)$.

Notice the usage of the negative increments (-1) for the push-down example of $\mathrm{b})$. This causes the assignment

$$
X(N+1)=X(N), X(N)=X(N-1), \ldots, X(2)=X(1)
$$


to be implemented in this order.

a) Extract and "pop"

$\mathrm{N}=\mathrm{N}-1$

$\mathrm{XO}=\mathrm{X}(1)$

$\mathrm{CAIJ} \operatorname{SCOPY}(\mathrm{N}, \mathrm{X}(2), 1, \mathrm{X}(1), 1)$

b) "Push-down" and insert

$\operatorname{CALI} \operatorname{SCOPY}(\mathbb{N}, \mathrm{X}(1),-1, \mathrm{X}(2),-1)$

$\mathrm{N}=\mathrm{N}+1$

$\mathrm{X}(1)=\mathrm{XO}$

Example 8

In this example we want to transpose an $\mathrm{N}$ by $\mathrm{N}$ matrix $\mathrm{A}$ in-place, (in-situ). Here MDA is the first dimensioning parameter of the array $A(*, *)$.

80

$$
\begin{aligned}
& \text { DO } 80 \mathrm{~J}=1, \mathbb{N} \\
& \text { CALL } \operatorname{SSWAP}(\mathbb{N}-J, A(J, J+1), M D A, A(J+1, J), I)
\end{aligned}
$$

\section{Example 9}

In this more complicated example we swap in-place (in-situ) the components of the vector

$$
\left(\mathrm{x}_{1}, \ldots, \mathrm{x}_{\mathrm{K}}, \mathrm{x}_{\mathrm{K}+1}, \ldots, \mathrm{x}_{\mathrm{N}}\right)^{\mathrm{T}}
$$

so they become

$$
\left(\mathrm{x}_{\mathrm{K}+1}, \ldots, \mathrm{x}_{\mathrm{N}}, \mathrm{x}_{1}, \ldots, \mathrm{x}_{\mathrm{K}}\right)^{\mathrm{T}}
$$

making repeated use of the "Pop" or "Push-down" operations.

$$
\begin{aligned}
& \mathrm{NMK}=\mathrm{N}-\mathrm{K} \\
& \text { IF (.NOT. (K.GT.O.AND.NMK.GT.O)) GO TO } 120 \\
& \text { IF (.NOT. (K.LT.NMK)) GO TO } 100 \\
& \text { DO } 90 \mathrm{I}=1, \mathrm{~K} \\
& \mathrm{~T}=\mathrm{X}(1) \\
& \operatorname{CALL} \operatorname{SCOPY}(N-1, X(2), 1, X(1), 1) \\
& X(N)=' L ' \\
& \text { GO TO } 120
\end{aligned}
$$$$
90
$$ 
100

CONTINUE

DO $110 \quad I=I, N M K$

$\mathrm{T}=\mathrm{X}(\mathrm{N})$

CALL SCOPY $(N-I, X(1),-1, X(2),-1)$

110 $\mathrm{X}(\mathrm{l})=\mathrm{T}$

120

CONTINUE 
Distribution:

1141 D. B. Holdridge

2610 R. E. Detry

2613 E. A. Aronson

2613 I. A. Bertram

2613 K. Haskell (20)

2613 R. E. Jones

2613 M. R. Scott

2613 W. Vandevender

2613 H. A. Watts

2640 J. L。 Tischhauser

2641 P. A. Lemke

2644 C. B. Bailey

5000 A. Narath

Attn: 5200 E. H. Beckner

5300 O. E. Jones

5400 A. W. Snyder

5700 J. H. Scott

5800 R. S. Claassen

5100 J. K. Galt

Attn: 5110 F. I. Vook

5130 G. A。 Samara

5150 J. E. Schirber

5120 G. J. Simmons

5160 W. Herrmann

5121 P. B. Bailey

5121 H T. Davis

5121 J. A. Davis

5121 C. A. Morgan

5121 P. J. Slater

5121 G. Po Steck

5121 R. J. Thompson

5122 D. E. Amos

5122 R. J. Hanson (50)

5122 K. L. Hiebert

5122 B. L. Hulme

5122 L. F. Shampine

5122 J. A. Wisniewski

5166 N. Ruiz

8266 E. A. Aas

8325 R. E. Huddleston

8325 T. H. Jefferson

3141 C. A. Pepmueller (Actg.) (5)

3151 W. L. Garner (3)

For DOE/TIC (Unlim. Release)

3172-3 R. Campbell (25)

For DOE/TIC 